Published in final edited form as:

Cell. 2009 August 7; 138(3): 606.e1-606.e2. doi:10.1016/j.cell.2009.07.020.

\title{
SnapShot: Effector and Memory T Cell Differentiation
}

\author{
Matthew E. Pipkin and Anjana Rao \\ Department of Pathology, Harvard Medical School, Boston, MA 02115, USA
}

\begin{abstract}
The differentiation of T cells is an ideal system to study the molecular basis of lineage specification in mammalian cells. Upon stimulation with antigen during infection or inflammation, naive peripheral $\mathrm{T}$ cells differentiate into various types of effector $\mathrm{T}$ cells with specific immune functions. Naive $\mathrm{CD}^{+} \mathrm{T}$ cells differentiate into at least four subsets (lineages) of T helper (Th) cells: Th1, Th2, Th17, or "induced" regulatory T cells (iTregs). Each subset is distinguished by the cytokines that they produce (Ansel et al., 2006; Lee et al., 2006; Zhou et al., 2009). Naive $\mathrm{CD} 8^{+} \mathrm{T}$ cells differentiate into effector cytolytic $\mathrm{T}$ lymphocytes $\left(\mathrm{CTL}_{\mathrm{Eff}}\right)$ that kill infected host cells using the poreforming protein perforin and serine esterases called granzymes (Cruz-Guilloty et al., 2009). Alternatively, naive $\mathrm{CD} 8^{+} \mathrm{T}$ cells can differentiate into memory CTLs $\left(\mathrm{CTL}_{\mathrm{Mem}}\right)$ that survive long-term and protect the host from reinfection (Kaech and Wherry, 2007). T cell differentiation is in large part determined by signals from the environment and is shaped by numerous feedback and feedforward loops (bold arrows) that modulate and reinforce the direction in which differentiation proceeds (Singh, 2007). Transcription factors (boxes) play a key role in this process by forming networks in which they reinforce or oppose each other's actions. This SnapShot illustrates the differentiation pathways for several of the best characterized T cell subsets.
\end{abstract}

\section{Naive}

The transcription factor ThPok and transcription factors of the Runx family act in an antagonistic fashion to specify the development of naive $\mathrm{CD} 4^{+}$and $\mathrm{CD} 8^{+} \alpha \beta \mathrm{T}$ cells that emigrate from the thymus and colonize peripheral lymphoid organs (Taniuchi, 2009).

\section{Antigen priming}

Upon encountering antigen and with costimulation by antigen-presenting cells, naive $\mathrm{T}$ cells initiate a generic transcription program called priming (thin black lines) that depends on the activation of widely expressed, latent transcription factors including NFAT, NF- $\kappa \mathrm{B}$, and AP-1 (Fos-Jun). These, in turn, induce expression or activation of secondary transcription factors such as the early growth response (Egr) proteins (not depicted). They also induce expression of the cytokine interleukin-2 (IL-2) and the $\alpha$ and $\beta$ chains of the IL-2 receptor (IL-2R). Binding of IL-2 to its receptor activates the Stat5 transcription factor. In certain settings, the transcription factors Blimp-1 and Bcl6 are induced and counteract each other's expression (Martins and Calame, 2008; Johnston et al., 2009). During this phase, T cells also promiscuously activate low-level transcription of most "lineage-specific" genes (not depicted). Such genes include those encoding the T-bet and Gata3 transcription factors that impose Th1 and Th2 lineage specification, respectively. T-bet and Gata3 are both transcribed early in activated T cells, but in the presence of the cytokine IL-4 that drives Th2 differentiation, Gata3 expression is sustained whereas T-bet expression is silenced, thus reinforcing Th2 lineage commitment. 


\section{Cytokine programming and stabilization of the effector phenotype}

Primed T cells quickly fall under the control of the cytokine environment. Cytokines program transcription factor networks that stabilize the phenotype and function of differentiating $\mathrm{CD}^{+} \mathrm{T}$ cells by driving chromatin modifications that activate lineagespecific and inactivate lineage-inappropriate genes (Ansel et al., 2006; Grogan et al., 2001; Lee et al., 2006). Key lineage-specific transcription factors-T-bet for Th1 cells, Gata3 for Th2 cells, ROR $\gamma$ t for Th17 cells, and Foxp3 for regulatory T cells-are distinguished by the fact that their ectopic overexpression in differentiating $\mathrm{T}$ cells induces "reprogramming" of those cells to the lineage that they control, even in the presence of cytokines that ordinarily program a different lineage. These lineage-specifying factors cooperate with stimulationinduced transcription factors through direct physical interactions (black lines without arrows) to mediate their effects (Ansel et al., 2006; Zhou et al., 2009).

Less is known about the transcriptional networks that program $\mathrm{CD}^{+} \mathrm{T}$ cell differentiation into effector and memory CTLs, partly because most experiments have been performed in mice infected with model pathogens (Kaech and Wherry, 2007). Many of these studies compared wild-type mice with mice carrying disrupted genes. Although genetic analyses can undoubtedly show that a missing gene product has a role in the development of effector or memory CTLs, such analyses cannot determine whether the role is direct or indirectadditional epistatic and biochemical analyses are needed, preferably using simplified cellculture systems such as those used to examine $\mathrm{CD} 4^{+} \mathrm{T}$ cell differentiation. Such systems have helped to clarify that the transcription factor Runx 3 is central to programming the function of CTLs, and that T-bet and Eomesodermin (Eomes) are induced in response to distinct signals and have distinct as well as redundant functions (Cruz-Guilloty et al., 2009).

\section{Effector function after re-encounter with antigen}

Early transcription factors act again, often cooperating with lineage-specific transcription factors at lineage-specific effector genes whose chromatin structure has been remodeled during differentiation for rapid, high-level transcriptional induction (Ansel et al., 2006).

\section{Abbreviations}

IL-2R, IL-4R,
IL-6R, IL-12R,
IL-21R, IL-23R
IFN- $\gamma$
TGF- $\beta$
T-bet
Stat
Hlx
Gfi-1
Gata3
ROR $\gamma$ t and $a$
RBPJx

IRF-4
Cytokines and receptors: Interleukin (IL-2, IL-4) and receptors

Interferon gamma

transforming growth factor $\beta$

Transcription factors: T-box expressed in T cells

signal transducer and activator of transcription 1, 3, 4, 5, 6

H2.0-like homeobox

Growth factor independent 1

GATA-binding protein 3

retinoic acid receptor related orphan receptor gamma $t$ and alpha

recombination signal binding protein for immunoglobulin kappa $\mathbf{J}$ region

interferon regulatory factor 4 


\begin{tabular}{|c|c|}
\hline $\mathbf{N F}-\boldsymbol{\kappa} \mathbf{B}$ & nuclear factor of kappa light polypeptide enhancer in B cells \\
\hline NFAT & nuclear factor of activated $\mathrm{T}$ cells \\
\hline Smads & $\begin{array}{l}\text { similar to mothers against decapentaplegic are TGF- } \beta \text { activated } \\
\text { transcription factors }\end{array}$ \\
\hline Foxp3 & forkhead box P3 \\
\hline Blimp-1 & B lymphocyte induced maturation protein 1 \\
\hline Bcl6 & B cell leukemia/lymphoma 6 \\
\hline Eomes & T-box factor Eomesodermin \\
\hline Id2 & inhibitor of DNA binding 2 \\
\hline Klf2 & Kruppel like factor 2 \\
\hline c-maf & musculoaponeurotic fibrosarcoma proto-oncogene \\
\hline ThPok & zinc finger and BTB domain containing 7B \\
\hline Runx3 & Runt related transcription factor 3 \\
\hline
\end{tabular}

\section{REFERENCES}

Ansel KM, Djuretic I, Tanasa B, Rao A. Regulation of Th2 differentiation and Il4 locus accessibility. Annu. Rev. Immunol. 2006; 24:607-656. [PubMed: 16551261]

Cruz-Guilloty F, Pipkin ME, Djuretic IM, Levanon D, Lotem J, Lichtenheld MG, Groner Y, Rao A. Runx3 and T-box proteins cooperate to establish the transcriptional program of effector CTLs. J. Exp. Med. 2009; 206:51-59. [PubMed: 19139168]

Grogan JL, Mohrs M, Harmon B, Lacy DA, Sedat JW, Locksley RM. Early transcription and silencing of cytokine genes underlie polarization of T helper cell subsets. Immunity. 2001; 14:205-215. [PubMed: 11290331]

Johnston RJ, Poholek AC, Ditoro D, Yusuf I, Eto D, Barnett B, Dent AL, Craft J, Crotty S. Bcl6 and Blimp-1 are reciprocal and antagonistic regulators of $\mathrm{T}$ follicular helper cell differentiation. Science. 2009 Published online July 16, 2009. 10.1126/science.1175870.

Kaech SM, Wherry EJ. Heterogeneity and cell-fate decisions in effector and memory CD8(+) T cell differentiation during viral infection. Immunity. 2007; 27:393-405. [PubMed: 17892848]

Lee GR, Kim ST, Spilianakis CG, Fields PE, Flavell RA. T helper cell differentiation: regulation by cis elements and epigenetics. Immunity. 2006; 24:369-379. [PubMed: 16618596]

Martins G, Calame K. Regulation and functions of Blimp-1 in T and B lymphocytes. Annu. Rev. Immunol. 2008; 26:133-169. [PubMed: 18370921]

Singh H. Shaping a helper T cell identity. Nat. Immunol. 2007; 8:119-120. [PubMed: 17242680]

Taniuchi I. Transcriptional regulation in helper versus cytotoxic-lineage decision. Curr. Opin. Immunol. 2009; 21:127-132. [PubMed: 19361971]

Zhou L, Chong MM, Littman DR. Plasticity of CD4+ T cell lineage differentiation. Immunity. 2009; 30:646-655. [PubMed: 19464987] 